\title{
Foreword
}

\section{Articular Cartilage}

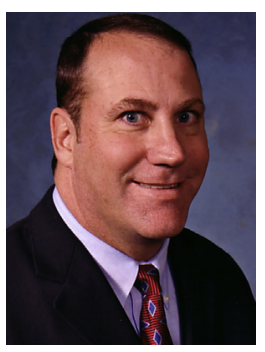

Mark D. Miller, MD Consulting Editor

"If we consult the standard Chirurgical Writers from Hippocrates down to the present Age, we shall find, that an ulcerated Cartilage is universally allowed to be a very troublesome Disease; that it admits of a Cure with more Difficulty than carious Bone; and that, when destroyed, it is not recovered."1

Special thanks to Dr Eric McCarty and his team of articular cartilage experts who have made giant strides in order to attempt to prove Dr Hunter's almost three-century-old characterization wrong. In his Preface, Eric referred to "gray-haired sports medicine physicians." As one of those myself, I certainly have more to learn, especially regarding this troublesome disease.

This issue of Clinics in Sports Medicine goes way beyond merely scratching the surface; it is a complete treatise on our current knowledge of articular cartilage diagnosis and treatment. Basic science and imaging are discussed as well as all treatment options, beginning with nonoperative treatment and then includes well-established options (microfracture, autograft, allograft, and cell-based) as well as newer procedures (including biologic options and "microfracture plus"). Although the knee is traditionally 
the target for these procedures, this issue also includes treatment options for the shoulder, hip, elbow, and ankle.

Great job on a troublesome topic-there is still much to learn and much to discover!

Mark D. Miller, MD

Division of Sports Medicine

Department of Orthopaedic Surgery

University of Virginia

400 Ray C. Hunt Drive, Suite 330

Charlottesville, VA 22908-0159, USA

E-mail address:

mdm3p@virginia.edu

\section{REFERENCE}

1. Hunter W. On the structure and diseases of articulating cartilages. Trans R Soc Lond 1743;42B:514-21. 